\title{
Literature review of bridge structure's optimization and it's development over time
}

\author{
Qasim Zaheer $^{1}$ (D), Tan Yonggang ${ }^{1}$, and Furqan Qamar $^{2, *}$ (D) \\ ${ }^{1}$ Dalian University of Technology Dalian, China \\ ${ }^{2}$ University of Warwick, CV4 7AL, UK
}

Received: 5 October 2021 / Accepted: 8 November 2021

\begin{abstract}
The structural development in bridge engineering along with efficiency have got much attention in few decades. Leading to the development, Optimization of structure established on mathematical analysis emerged mostly employed strategies for productive and sustainable design in the bridge engineering. Despite the widespread knowledge, there has yet to be a rigorous examination of recent structural optimization exploration development. Thus, the primary objectives of this paper are to critically review previous structural optimization research, provide a detailed examination of optimization goals and outline recent research field limitations and provide guidelines for future research proposal in the field of bridge engineering structural optimization. This article begins by outlining the relevance of efficiency and sustainability in the bridge construction, as well as the work done required for this review. Suitable papers are gathered and followed by a statistical analysis of the selected publications. Following that, the selected papers are evaluated in terms of the optimization targets as well as their spatial patterns. Structure's optimization four key steps, including modeling, optimization techniques, formulation of optimization concerns and computational tools, are also researched and examined in depth. Finally, research gaps in contemporary works are identified, as well as suggested guidance for future works.
\end{abstract}

Keywords: Metaheuristic algorithm / bridge structure / bridge optimization / critical review of bridge optimization

\section{Introduction}

Bridge engineering field is basically a vocation that deals with study of design, function, maintenance, construction, and development related to road infrastructures having various kinds of works in bridges, for instance piling, and culverts [1]. However, the low efficiency, high labor intensity and increasing environmental effects [2-4] are often understood trade by the architecture, engineering and construction industry while a huge fraction of saving is part of it as well. According to Karen Manley, Tim Rose's report et al. [5], the nearly $9 \%$ of the World GDP is made up by the accepted construction business. In 2017 another survey from [6] is carried out according to that, construction industry is the 2nd largest china's energy consuming sector. Estimating 20\% of entire energy utilization, almost $23 \%$ of total electric power usage and approximately $30 \%$ carbon emission $\left(\mathrm{CO}_{2}\right)$ which is throwing remarkable effects on the climate. Therefore, it is core interest of all in boosting economic, social, and environmental ability of

\footnotetext{
* email: drfurqanqamar@warwickgrad.net
}

bridge engineering activities. With the start of 20th century, birth and growth of computational methodology for structural design and analysis, in a past few decades it has been observing that optimization techniques build on the mathematical programming methods have been formulated and also approved in bridge engineering and it pertains to pile up the best effect under particular circumstances $[7,8]$.

In bridge engineering the optimization may enforce in every stage of project from its design to its construction or supervision. The structural optimization is one the most utilized divisions of optimization. In this survey, to attain the different goals under given circumstances, "structural optimization" means to explore the decent arrangement of structural elements and also dismissing the properties of approved materials [9]. The crucial and essential part of bridge engineering structure is 'material' which has the greater part in their achievement. In bridge engineering infrastructures [10], concrete-based composite materials are widely used in which ordinary concrete, enhanced concrete, pre-stressed concrete etc are involved [11]. Although bridge engineering structures have different kinds of materials, but sole type of material is generally 
understood in structural optimization because of the computational complications when material distribution are contemplated.

Structural optimization is further categorized into four types [12]:

- Size optimization: leads to the cross-sectional volume of structures or structural components as design variable [13];

- Shape optimization: Shape optimization: it has another name "configuration optimization" that leads to the structure's nodal coordinate changes and act as design variables [14];

- Topology optimization: intends to eliminate unwanted structural components to attain the optimum solution in design as well as concentrates on how joints are attached and supported [15];

- Multi-objective optimization: for better optimization results [16], this optimization understood multiple of the mentioned optimization goals; an optimization implicated shape, size as well as topology in parallels time frame also known as layout optimization [17].

In the initial step, area of bridge engineering studies on optimization only consists of mathematical proofs and programming methods, they rely on simple structure as model. Structural optimization has been pertained to more complicated bridge engineering structures, especially topology optimization [9] due to the improvement of computational and construction method. Further illustration of optimization application of structure, concerned to large-scale bridge engineering project is, Dalian suspension bridge china.

The optimized exoskeleton member layout increased the material performance through the help of topology optimization boosted design while the widespread stiffness the structure was ensured [18]. Structural optimization has one of the main purposes to minimize the gross expense of structure [19]. In infrastructure works, the regulations of structural achievement wished on the assumption of convincing is always a lower expenditure. By decreasing the full weight of structure in order to curtail the whole cost, for this purpose various kinds of researches have been documented. Recently, with the uplift probe on the environmental problem and considerable improvement, another substantial purpose of structural optimization has been evolved by lessening environmental consequences just due to significant quantity of $\mathrm{CO}_{2}$ emissions in area of construction engineering [20]. In improvement, enhancing certain structural achievements, Le [21] emphasized by some study manuscripts on structural optimization such as dynamic seismic performance, aerodynamic performance and mechanical behavior [22] to make structure friendly for various regions and their ecosystem.

Several optimization techniques have been composed and formulated in order to get the aims those are described above. Recently, in bridge engineering structural optimization exploration, the metaheuristic techniques have the significant optimization techniques because they are adequate for combinatorial optimization difficulties. However, there are some disadvantages of metaheuristic techniques i.e. the high complexity [23], and deficiency for high-dimensional dilemmas [24], etc. Therefore, big numbers of researchers documented to concentrate on increasing the achievement of improvement (optimization) techniques either to recommend unique optimization techniques or to improve the prevailing metaheuristic techniques. For instance, to increase the execution of interactive search algorithm (ISA) for sizing of structure size and topology improvement, Mor Razavi [25] recommended an auxiliary fuzzy judgment mechanism. Less computational cost and bigger outcome precision are attained by the Fuzzy Adapted Interactive Search Algorithm (FTISA). From several trials that are based on the empirical findings, the new algorithm is verified to have a higher convergence momentum, lower computational expense and better optimization results as compared to the conventional harmony search algorithm. Topology optimization [26] exemplified that can achieve the optimum result more smartly related to many more state-ofthe-art mathematical algorithms described topology optimization technique such as the transformable triangular mesh (TTM) technique. In the domain of structural optimization these above described research explained the ability and achievements of structural optimization to increase the working and quality of structural engineering especially in bridges [27]. Nevertheless, although in field of bridge optimization considerable amount of surveys and research summaries were printed, none of them fulfilled the thorough view of the exploration improvement in structural optimization. Thus, in the field of bridge engineering this article endeavors to thoroughly survey the state-ofthe-art publications in area of structural optimization. It includes analysis of the optimization aims, and its worldly and spatial changes, examination of optimization processes with four important points, arguments of exploration, drawbacks and proposals of coming works.

The remaining of the manuscript is comprised of interpretation. Section 2 leads to the procedure that is for literature retrieval. As far as Section 3 concerns, it explicit a statistical data of the chosen manuscripts. In Section 4, the optimization objectives of the specified papers are classified and analyzed with respect to the temporal and spatial trends. Section 5 provides a complete analysis, survey and basic of the structural optimization techniques according to four possibilities, comprising modeling, problems of optimization formulation, structural analysis optimization methodologies, design platforms, and computational tools. In Section 6 implicit the constraints of the existing study and is founded on which magnifies the probable future works. In Section 7, finally decisions are taken out to conclude and outline this work.

\section{Methodology}

This research takes a comprehensive strategy to critically examine current state-of-the-art research work and illustrate comprehensive overview of structural optimization in area of bridge engineering. The investigation was limited to English-language materials published between the 1970s and February 2021. Figure 1 depicts the entire procedure of the survey, which includes selection of specific literature 


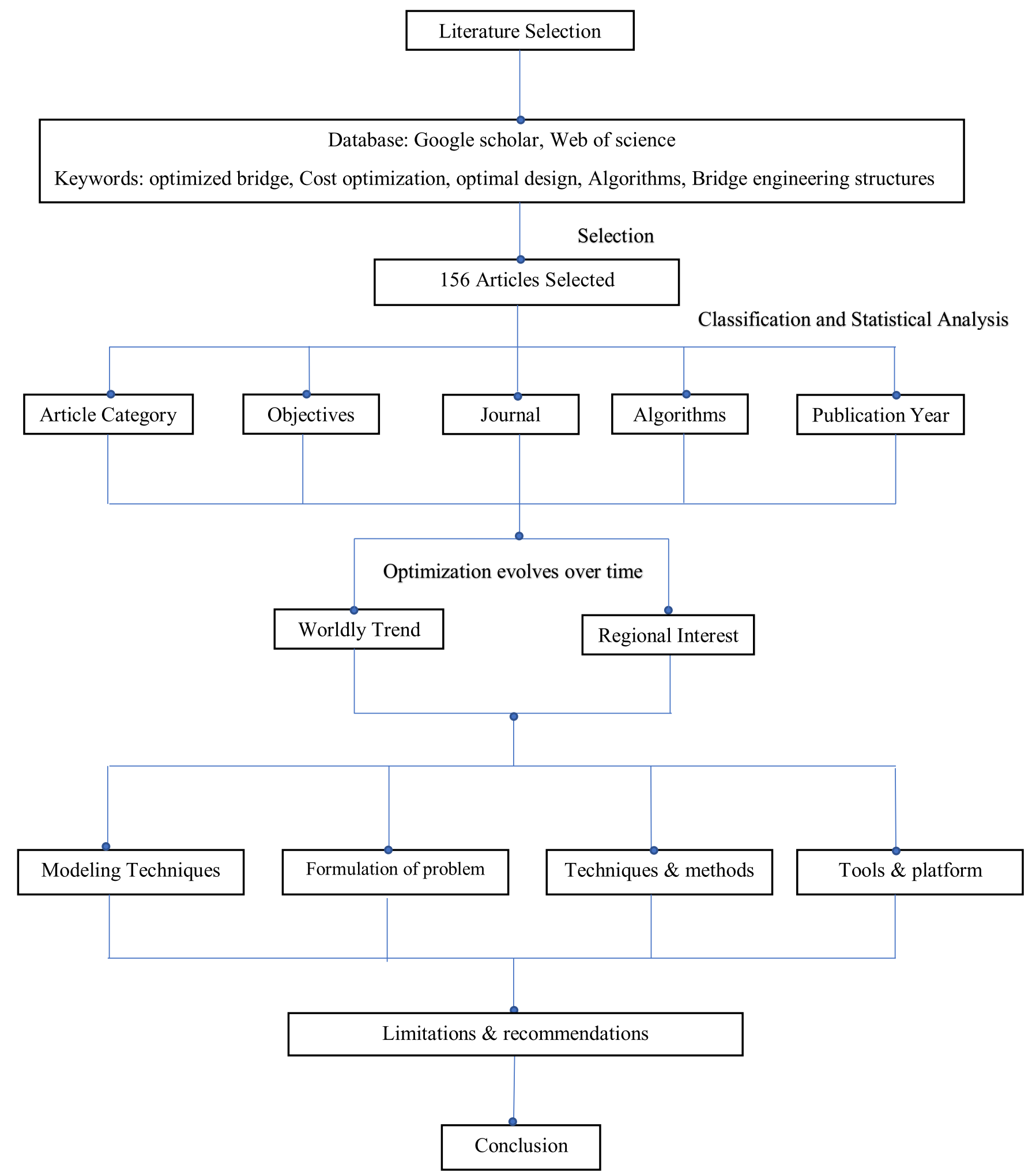

Fig. 1. Demonstration of research methodology. 


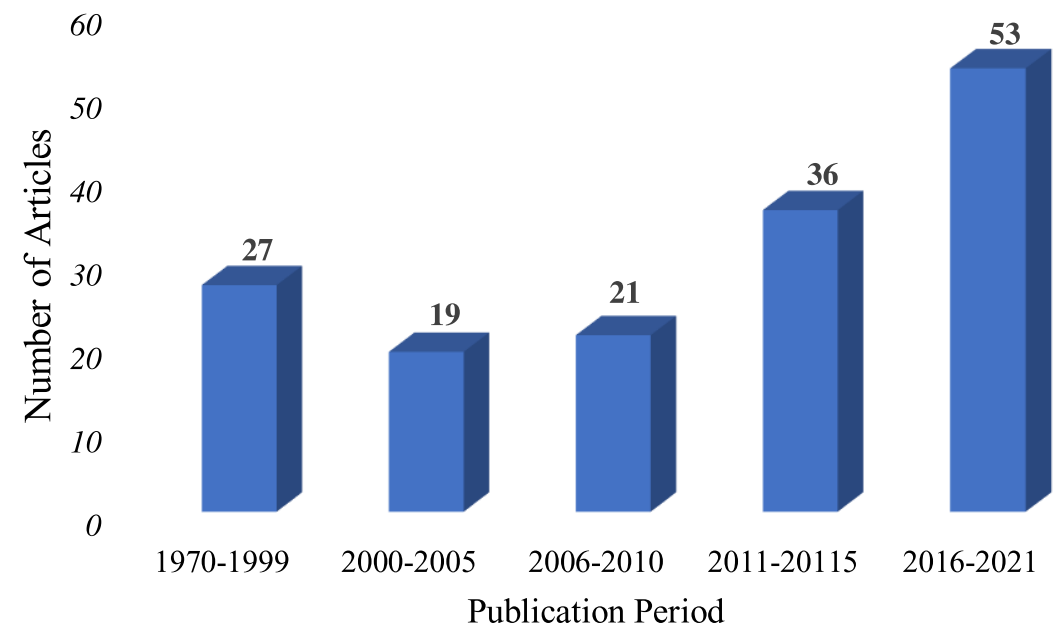

Fig. 2. Selected articles publication period.

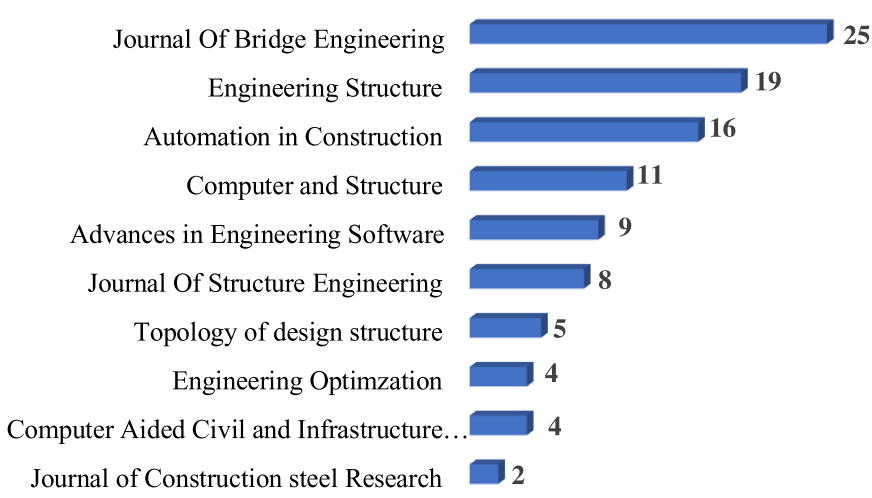

Number of Articles

Fig. 3. Selected articles from each journal.

from internet database, statistical evaluation of the chosen literature, a deep study about optimization objectives with regional and periodic trends, study of the optimization procedure, drawbacks, and research gap and its proposal, as well as a conclusion. Section 2.1 delves into the technicalities of literature selection, while Section 2.2 gives a quick rundown of the keywords employed in the process. To avoid duplication, all references from the selected publications were double-checked for relevant research that may have been missed during the electronic and manual searches.

\subsection{Literature retrieval}

Publications about bridge optimization, which make up the majority of the academic literature published, were found using the electronic databases Scopus, Google Scholar and Web of Science. Passing structural optimization, layout, size, shape, topology, optimum design, civil and bridge engineering structures, and metaheuristic approaches are utilized as search phrases to make literature retrieval convenient and easier. From the search results, the most relevant information was hand-picked.

A total of 156 papers were chosen using the aforementioned literature retrieval approach, including 125 research publications, 10 conference papers, 4 chapter from different books, 9 review papers, and 8 thesis. Despite its long history, structural optimization was first used in the aircraft industry, and it was only much later that it was applied to civil engineering [28]. Furthermore, as information technology has advanced, the optimization tactics used in current studies have drastically changed from those used in previous studies.

\subsection{Keywords for literature selection}

The research was conducted using a Boolean search strategy involving the phrases AND, OR, and ("Bridge Optimization") AND ("optimization" OR "optimal" OR "optimum" OR "minimal cost" OR "least cost"). To distinguish the type of structure explored in this study, the term "bridge optimization" was coined. The phrases "optimal", "minimum cost", "optimization", "optimum", and "least-cost" were used to discover works that employed optimization algorithms, whereas research papers that did not use optimization methods were deleted because these terms are commonly used in this field's literature search.

\section{Statistical data analysis of literature}

The chosen literature ratio of publications is shown in Figure 2 over time. The study started in 1970 and lasted for five decades. Structure optimization is becoming more popular and attracting increasing academic interest, according to the literature review. Eighty three percent of these research were published after the year 2000, from the percentage of total data fifty seven percent were 


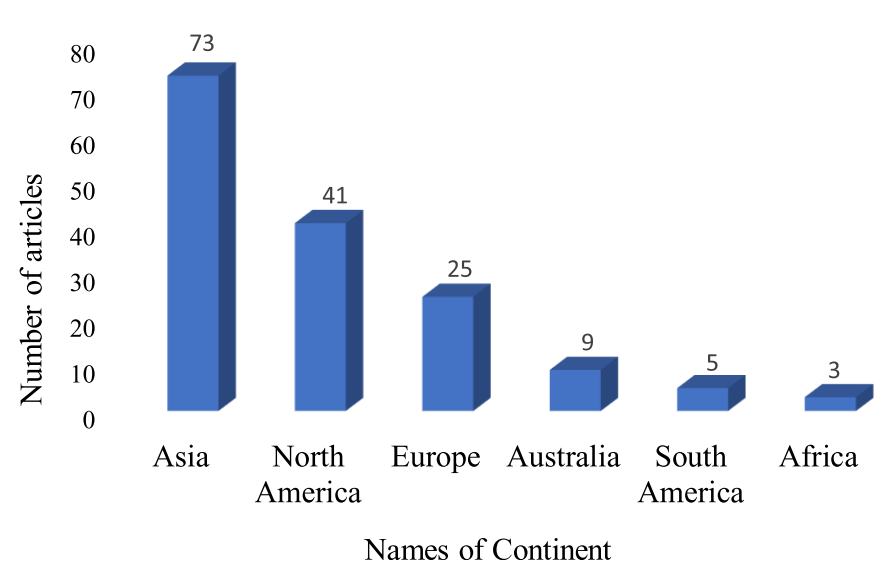

Fig. 4. Selected articles from different continents.

\section{DATA CONTRIBUTION}
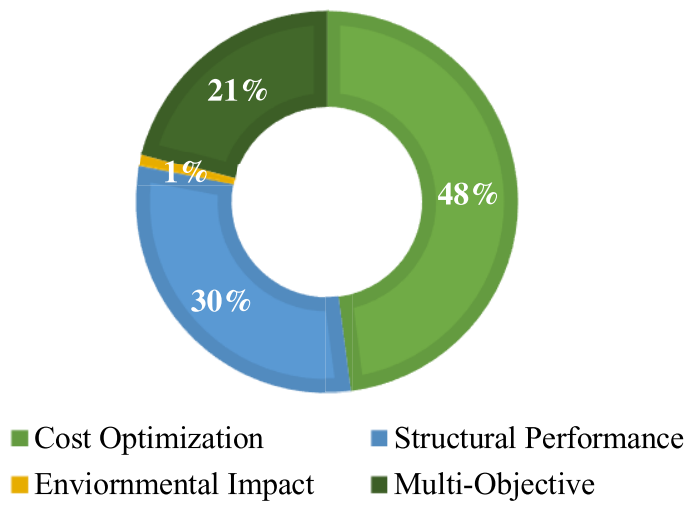

Fig. 5. Proportion of papers for their objectives.

Table 1. Summary of Optimization objectives with references.

\begin{tabular}{lll}
\hline Objective & Brief Description & Related Study \\
\hline Cost minimization & $\begin{array}{l}\text { Optimization to reduce cost of bridge, that } \\
\text { usually attained by reducing structure's volume. }\end{array}$ & {$[110-117]$} \\
Structural performance development & $\begin{array}{l}\text { Optimization for the improvement of some } \\
\text { structural properties in order to order to adapt } \\
\text { functional requirements } \\
\text { Environmental impact minimization }\end{array}$ & $\begin{array}{l}\text { Optimization to reduce the impact of bridge } \\
\text { construction on environment. i.e. emission of } \\
\text { gases, bridge in water, material impact of species } \\
\text { living in water } \\
\text { Multi-objective }\end{array}$ \\
\hline
\end{tabular}

published from 2011 to 2021 . Our case is aided by the fact that data is readily available (that garnering attention from researchers takes time).

These papers were evaluated using the sources that publish the most papers on the topic of Bridge engineering structures optimization. In well-known and famous ten journals, a total of 103 papers have been published. Journal of Bridge Engineering takes the lead with 25 articles, followed by Engineering Structures and Computer Structures, each with more than 15 papers.

Furthermore, as shown in Figure 4, the retrieved publications are separated into regions based on the chief author's research school/geographical institute affiliation. With 73, 41, and 25 articles published, Asia, North America, and Europe are the top three continents, accounting for 93 percent of the total number of publications.

\section{Objectives of structural optimization}

\subsection{Categories of optimization objectives}

The four classes below can be used to classify the optimization goals of the structural optimization studies that have been chosen:
- Cost minimization: The purpose of structural optimization design is to reduce total cost, which is usually accomplished by reducing the weight or volume of the structure.

- Structural performance development: The purpose of structural optimization design is to improve certain structural features such as mechanical behavior, aerodynamic achievement, and dynamic seismic performance in order to meet requirements under varied scenarios [29].

- Minimization of environmental impact: The purpose of structural optimization design is to reduce greenhouse gas emissions or energy consumption in order to improve the environmental performance of the structure.

- Multi-objective optimization: a single optimization that incorporates more than one of the three objectives [30].

Table 1 presents a detail of the four classes of optimization objectives with References.

The percentage of articles picked for each optimization goal is shown in Figure 5. The majority of the investigators, who account for 48 percent of the papers picked, are project stakeholders who are focused on cost reduction. Another $30 \%$ of the papers assessed use structural optimization to increase structural achievement, while another $21 \%$ use structural optimization to achieve multiple goals. Only $1 \%$ of the papers selected are solely focused on curtailing the 
bad environmental impact on and due to bridge structures. The explanation for this could be that lowering the total cost of structures by controlling greenhouse gas emissions and also embodied energy use at the same time [31]. As a result, multi-objective optimization is a prominent technique in this industry, as it targets both cost and environmental effect mitigation at the same time.

\subsection{Temporal changes of optimization objectives}

The entire trend in bridge engineering structural optimization research has risen over time, while the proportion of papers devoted to each goal has shifted. Figures 6 and 7 show the quantity and ratio of articles respective of their optimization goal in each of the five intervals to assess differences in study progress in domain where structures are optimized over decades. Prior to year 2000, the article's primary focus was on cost reduction. This topic is mentioned in nine articles, accounting for $65 \%$ of all studies published before 2000. Because the weight or volume of a structure accounts for such large amount of its cost [9], all of the early studies concentrated to make structure lighter in volume. Quite less studies focus on structural working enhancement and multi-objective optimization that contain 16 percent and 15 percent of the publications respectively. In addition to cost reduction. All of the research published during this time period that tries to improve structural performance uses topology optimization [31], which comprises eliminating subsystems that make small contributions to structural performance while adhering to established standards [32]. Because these studies did not use a single structural performance parameter, various performance metrics such as obedience [33], ultimate displacement [34] and moment ("Analysis of Load Optimization in Cable Stayed Bridge Using CSI Bridge Software Load Optimization in Cable Stayed Bridge" 2018) were used to optimize the results.

The initial study cited in this paper performed separate mean compliance and weight minimizations before integrating the two types of optimizations to perform multiobjective structural optimization (Algorithm, n.d.). Multiobjective optimization is more typical when two objectives are considered at the same time. Shifting multi-objective problems with single-objective problems, some scholars offered a multiplier [35] while others employed a Pareto solution to simultaneously achieve several optimization goals [36].

After 2000, the amount of publications in domain of structural optimization skyrockets, particularly in the fourth phase, from 21 papers in 2006 to 36 manuscripts in 2011, with the percentage of articles meeting each target continuously increasing. As shown in Figures 6 and 7, cost reduction has always been a hot research topic, and the number of papers on the subject has increased fourfold since 2000. However, the ratio of this theme is lower in the last four time intervals (before 2000) than in the first (54 percent, 59 percent, 67 percent, and 58 percent, respectively). Structure's performance enhancement is the $2^{\text {nd }}$ most popular area, accounting for $24 \%$ of all stated papers. Since 2000 , the number of papers with this purpose has risen in each of the four different time periods. This

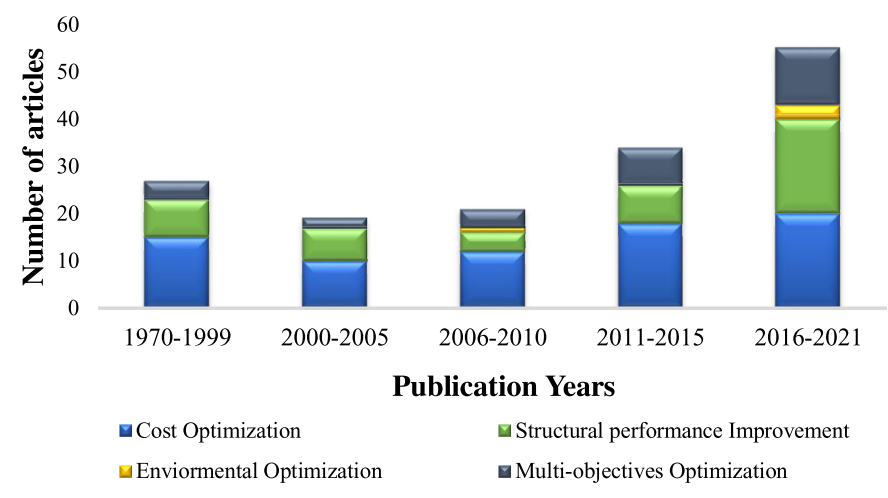

Fig. 6. Number of papers and publication time with objectives.

structural optimization is vital when the security and

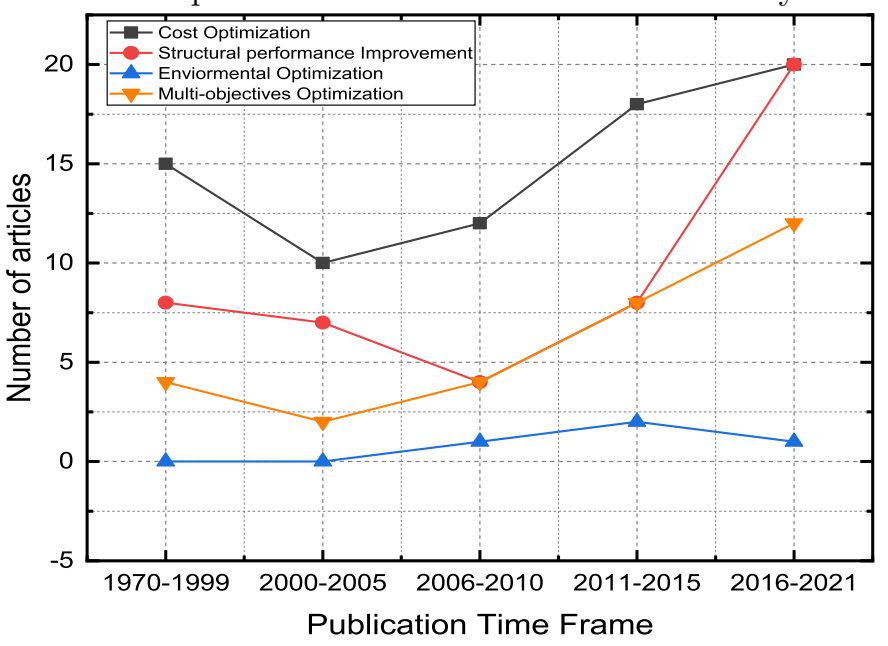

Fig. 7. How structural optimization changes over time.

service is on priority than cost (weight) reduction [37]. Furthermore, few academics use structural optimization to achieve multiple aims at the same time. These objectives are frequently incompatible and competitive [38]. Due to constraints such as computational complexity and outcome uncertainty, number of surveys associated to this subject are very limited, accounting for 16 percent of the total papers selected [39], Figure 6 shows how the number of multi-objective research has fluctuated since 2000. Since 2000 , the number of multi-objective studies has fluctuated as shown in Figure 7. Furthermore, three of the five pieces were produced between 2016 and 2021, indicating that this topic may become more popular in the future as concerns about bridge engineering's long-term viability develop [40].

\subsection{Spatial changes of optimization objective}

Financing from the public institutions or private authorities heads towards an increase in the number of research publications produced in specific topics on average. In a previous review paper [41], the phrase "geographical scope" was used to characterize the division of geographical areas. 


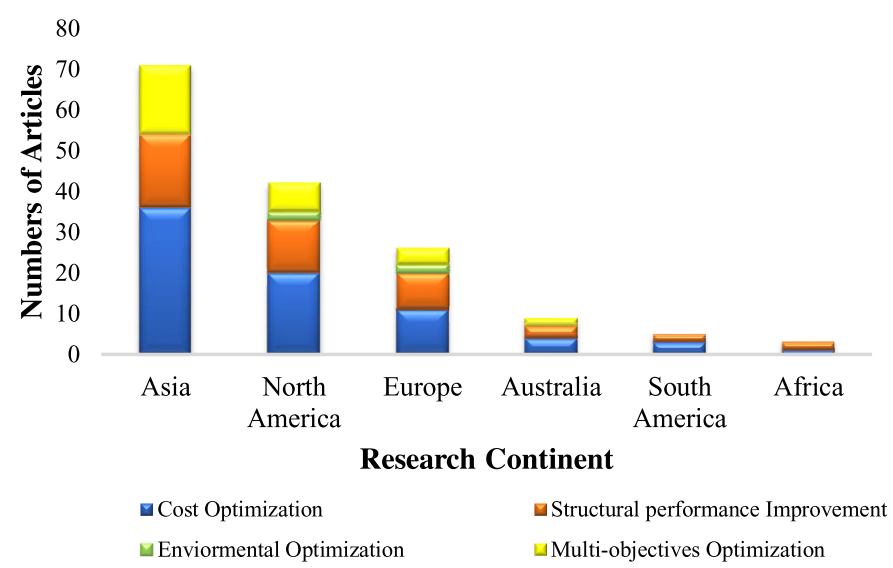

Fig. 8. Distribution of gathered manuscripts in each continent.

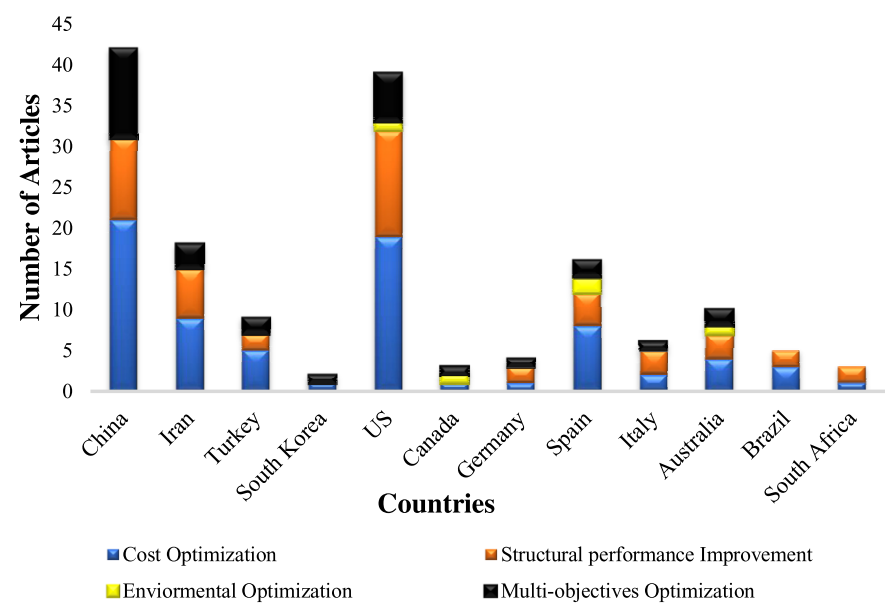

Fig. 9. Distribution of gathered manuscripts in countries.

Figure 5 depicts the proportion of articles collected by continent, with Asia, Europe, and North America being the most major landmasses with the most publications. For each optimization target, Figure 8 displays the distribution of gathered manuscripts in each continent. Across all continents, cost minimization appears to be the most popular topic. However, in entire Europe continent and North American, the volume of conversation on this issue is only somewhat minor than in entire Asia. One more discrepancy is that environmental effect mitigation research is found in Europe and North America but not in Asia. Each of the other three continents received only two, five, and eight pieces, respectively (Africa, South America, and Oceania, respectively). This means that structural optimization-related investigation is quite basic in these areas.

The geographical scope was subsequently broadened to cover the specific territory in order to assess geographical research directions in the area of bridge structural optimization. Total 156 papers are collected for this review came from 50 different states. Figure 8 shows the top 12 countries in terms of the number of manuscripts collected and articles submitted. The leading four countries having the most publications and selected in this review are China, the United States of America, Iran, and Spain. A total of 115 articles have been brought up online by researchers mostly from these four states, containing $73 \%$ total number of papers collected. Various studies objectives are evenly scattered in states with good economy (China, the United States, Australia, South Korea, Canada, Italy, Turkey, Spain and Germany), whereas in states with somewhat poor economy (Iran, Brazil, South Africa, India, and Pakistan), the study mainly concentrates on cost minimization. In countries with seismically active zones, such as United States, China, South Korea, and Japan, more research on structural performance development has been discovered. This suggests that geographic and environmental factors can have an impact on exploratory routes [27]. Researchers in these countries are more motivated to improve structural performance in the face of earthquakes and seismic loads [42].

\section{Process of structural optimization}

In bridge structures, there are various structural optimization items such as the pier, girder, steel sections, cables, and so on, but modular structures; frames and trusses are the most often used. When using structural optimization techniques, four fundamental factors should be kept in mind:

- A structural analysis and design modeling technique that distinguishes between discrete and continuous structural optimization;

- Definition of optimization problem, in addition with objective function(s), variable descriptions, and constraint descriptions.

- Optimization strategy, which deals with the mathematical programming approaches that are used to get optimum structure;

- Design platform and Computational tool, which deals with software strategies that are employed to drive the optimization programs and codes to carry out optimal design.

\subsection{Modelling techniques for design and analysis of structure}

Optimization of structure is iterative process in its nature. Structural analysis must be run numerous times during the optimization process to examine the evolution of every design till the achievement of convergence that is significant computational cost. As a result, selecting a computationally sound structural analysis technique is crucial, particularly for big, complex bridge engineering projects. In structural analysis, the finite element method (FEM) is extensively employed to reduce computational costs, with basic finite element models being utilized more frequently than complicated finite element models. The next cost-cutting alternative is the simultaneous analysis and design strategy, which integrates structural analysis 
with structural design $[43,44]$. Structural optimization can be classified into two groups based on the modeling approaches adopted in early stages of design procedure: discrete optimization and continuous optimization. Structure network is molded with discrete structural components in discrete optimization, however the structure network systems taken as solid continuum when have inconsistent topology in continuum optimization [45].

Because structures distributed into few components, cross-sectional characteristics and nodal locations are useful in the discrete optimization technique. As a result, when given a stated and constrained topology. This phenomenon is frequently utilized in optimizing shape and size and a sort of optimization technique that focuses these components is known as pre-defined or no topological optimization [46]. To put it another way, topological optimization is the process of selecting a structure's form, whereas shape optimization is the process of modifying a structure's shape to enhance its desired properties (usually mass volume or weight) [47] illustrate pre-defined topological optimization. The connection of structural components is generally the subject of the discrete optimization approach for topology optimization. The best design elements from each part may be merged to create a full perfect design.

This method is frequently associated with topology optimization, which is used to solve material distribution difficulties [48]. The ideal design are not always result in truss or girder like structural components, continuum optimization strategy outperforms the discrete optimization technique to some extent. However, the applicability of the continuum strategies with in domain of bridge engineering are restricted since the problem to be optimized is more complex and the method of programming is more harder than dealing with discrete sections of the structure [45].

\subsection{Formulation of optimization problems}

Problem or research gap formulation relates basic three components in optimizing a problem: objective function(s), constraints and design variables, within problem search area [27]. Presuppositions are used to alter the attributes of component when performing structural optimization. The parameters that are utilized to indicate how these traits change are known as design variables, denoted as a vector. The two types of design variables that can be categorized depending on their relevance are continuous and discrete design variables. Discrete design variables have values that are separated, whereas continuous design variables have discrete values that change within range. A function (or combination of functions) that can be used to calculate the outcome of an optimization is known as an objective function. Constraints are security and serviceability constraints that must be met during the optimization process. Equality and inequality restrictions are two distinct types of limits that can be applied in various ways. Possible they can be combined to declare few optimization strategies. For instance, equality constraint $H(X)=0$ renovated by couple of inequality constraints $H 1(X) \geq 0$ and $H 2(X) \leq 0$. Constraints, incorporated into the objective function as penalty functions to shift it from a limited to unconstrained state [27] limits of design variables are known as design space or search space, and it can be separated to two domains: infeasible and feasible. The viable domain is made up of design junctures that meet all of the criteria, whereas the infeasible realm is made up of design degrees that break at least one constraint constant. The following is the most typical understanding of an optimization problem [13]:

$f(x)=$ Objective Function (minimization or maximization)

$$
\begin{aligned}
& B_{i}(X) \leq 0, \text { where } i=1,2,3 \ldots \ldots m \\
& C_{j}(X)=0, \text { where } j=1,2,3 \ldots . p
\end{aligned}
$$

$X \in S$

where $X$ is a vector $X=[X 1, X 2, X 3 \ldots . X \mathrm{n}]$ and exemplifies the design set of variables, where $\mathrm{n}$ denotes number of design variables; $\mathrm{f}(X)$ is the objective function; $B_{i}(X)$ and $C_{j}(X)$ pertain both inequality and equality constraints; $p$ and $m$ are numbers of constraints, and $\mathrm{S}$ is denoted for design or search space.

As previously indicated, structural optimization includes four sorts of aims. As a consequence, the objective category will be used to evaluate the issue formulation. The process of learning desired quantification of finding for an optimization issue, while convincing few regulations is known as interpreting the objective function. As a result, the parameter depicting the objective function may differ from the optimization target in some cases. The most widely acknowledged aim in structural optimization, cost reduction, is typically assessed to set up the volume of structure for target purpose. Nonetheless, structural designers sometimes criticize the use of weight to influence cost since a structured design with the least weight does not always imply the lowest cost [49]. As a result, certain objective functions are developed to handle cost reduction, but due to the worries and fuzziness experienced, small number of bridge engineering articles with in optimization domain, stress this area. The overall structure's volume is directly affected by to the cross-sectional characteristics of structural component, structural system is frequently scattered in several structural components, with crosssectional worth chosen for design variables. Objective function can be interpreted since the ratio of various materials is not taken into account in these studies as Equation below [50]:

$$
W=\sum_{i=1}^{n} \gamma \mathrm{aAiDi}
$$

where $W$ represents overall weight of member; $\gamma$ density; a denotes gravitational acceleration; and $\mathrm{X}=\{\mathrm{A} 1, \mathrm{~A} 2, \mathrm{~A} 3$, A $4 \ldots \ldots . . . A n\}$ the cross-sectional areas of structural components are denoted by $\mathrm{Ai}$, while the length of each 
structural member is denoted by Di. To reduce weight, this form of optimization of structure is usually coupled with sizing (size optimization) [50-52]. That structural optimization is concerned much in determining the best link between nodes, or if structural components should be present between nodes. The ground structure, which is a predetermined big structure with large number of structural components, usually starting point for topology optimization. Excess components are continually removed during the optimization process until the best design with the lowest weight is attained [53]. Vector always used to represent collection of topological variables. They have two degrees of significance for variables: 1 and 0 . Suppose value of a topological variable is 1 , the component of structure indicated by variable may be deleted; if the value is 0 , the portion cannot be eliminated. Structural topology optimization is commonly coupled with sizing for structure volume minimization to structural components with extremely minute cross-sectional occupancy are viewed as superfluous and can be eliminated [54]. Rather than the type of optimization, the specific design requirements are depending on the geographical specifications utilized. Stress and displacement limits are commonly achieved in structural optimization with the goal of lowering costs. The AASHTO, Euro-codes 2, and ACI Codes for Concrete, as well as British Standards, are some of the most commonly used regional standards [27].

Another common goal for structural optimization is to improve structural performance. In any case, there are no uniform standards for evaluating structural performance. You can choose from a variety of performance indices such as stiffness [18], compliance [55], strain energy [17], and static displacement [69] Manipulation of the gathered works establishes the objective function. The majority of the articles in this article that attempt to enhance structural performance employ topology optimization. The reason for this might be that, in principle, topology optimization leads to the ideal structural size, which can then be further enhanced using size and/or shape optimization approaches [56]. Compliance reduction is usually used as the goal function in this form of structural optimization to optimize the stiffness of structures. The goal might be stated as in equation [57]:

$$
\text { Minimum : } C_{P}=F^{T} \times Q(x)
$$

where $C_{P}$ is the compliance of member (structure); F indicates the load vector, and $Q$ refers to the displacement vector. Limits of structure's optimization for the performance development of structure are further distinct compare to those for volume reduction due to the several design rules for structural features. Natural regularity is constantly restricted when considering the dynamic response of structures, for example, to avoid the damaging consequences of dynamic loads [58]. This category of structural optimization accomplishes distinct mechanical constraints of structure such as stiffness, buckling loads, stress, and displacement based on design criteria. More, material volume limits are frequently used to keep bridge structural costs in check [59].
Academics have paid little attention to the third goal of structural optimization, which is to decrease environmental impacts. There have only been four works discovered on this subject. The environmental effect of bridge engineering constructions is measured in $\mathrm{CO}_{2}$ emissions or in energy usage in these studies, and the environmental impact is decreased by reducing the amount of material utilized [60]. In the same manner that cost-cutting restrictions are accepted, security and serviceability needs are accepted to induce design provisions [61].

In the bridge engineering business, there is always an uniform criteria for analyzing a project, which is to reduce costs while increasing security and serviceability. However, these goals may conflict with one another, meaning that improving one may result in the deterioration of another. Thus, in the realm of structural optimization, boosting studies have focused on balancing conflicting goals (typically two objectives) [62]. Multiobjective optimization is the name given to this form of structural optimization, and it is the last category of structural optimization goal discussed in this article. The fact that multi-objective optimization considers several objective functions distinguishes it from singleobjective optimization. For example, researchers may look at reducing both weight and deflection at the same time [63,64]. Multi-objective optimization problems are more difficult to solve, necessitating the use of more advanced computational techniques [65]. Another significant point of contention is that, contrary to multiobjective optimization's fundamental nature, there is no unique solution that accomplishes the best of all objectives at the same time [66]. Normally, a multiobjective optimum difficulty can be developed as Equation [67]:

Minimization function

$$
F(x)=\left[F_{1}(x), F_{2}(x), F_{3}(x) \ldots \ldots \ldots . . . F_{k}(x)\right]^{T}
$$

whereas

$$
\begin{aligned}
& B_{i}(X) \geq 0, \quad i=1,2,3 \ldots \ldots m \\
& C_{j}(X)=0, \quad j=1,2,3 \ldots \ldots p
\end{aligned}
$$

$X \in S$

where $F(x)$ denotes objective function's set; $B_{i}(X)$ and $C_{j}(X)$ showing both inequality and equality constraints; $\mathrm{X}=\left[x_{1}, x_{2}, x_{3}, \ldots \ldots, x_{\mathrm{n}}\right]$ design variables set; and $\mathrm{S}$ is the design space of outcome. Previously stated, the formulation yields no particularly good optimum treatment, and the optimization result is a collection of trade-off findings [68]. The Pareto optimum set [69], is made up of these results, which are referred to as no-dominated results. Pareto optimum set also known as Pareto front [69], that a useful tool for displaying results of multi-objective optimization when it schemes in coordinate system according to design standards. Making trade-off judgments on competing aims benefits designer. The constraint is a set 
of restrictions for each goal in multi-objective optimization, such as deflection constraints, volume constraints, mechanical constraints, and so on.

The framing of the issue is crucial in optimization of structure. It describes the variables, objectives, constraints, and solution scope. The optimization step next involves acquiring computational tools and techniques in order to identify the optimum solution(s) in the design space (search space).

\subsection{Optimization techniques and methods}

During the twentieth century, structural optimization was one of the most frequently researched subject areas in engineering. The 1951 paper by Kuhn and Tucker [70], was a seminal work in this field since it linked several key mathematical programming method for optimization of structure, such as the Lagrange multiplier approach, the equivalence theorem, and so on. In the future, these approaches will be used often. In modern time, numerical research methods and mathematical programming have become renowned methodologies to effectively seek for the best conclusion in the field of structure optimization. The best technique for finding a solution often begins with a preliminary design and iterates the value of goal until convergence [71]. In bridge engineering structural optimization, two types of optimization techniques are commonly used: heuristic and gradient-based approaches.

Gradient-based approaches anticipate predetermined investigation direction, which is called as gradient, prior to look for best result [72]. This optimization strategy can be more classified in four main groups: linear programming techniques, nonlinear programming techniques, optimality criteria techniques, and feasible direction techniques are all examples of linear programming techniques.

Linear programming techniques are optimization methods that use linear objective functions and restrictions. While one among them is non-linear, that techniques of optimization are known as non-linear programming techniques. Developing efficient techniques for the structural optimization with stiffness limitations placed on statically determinate or indeterminate structures, as well as structural dynamics principles, are all part of the optimality standards approaches [55]. The Lagrange multipliers are used to find local minima and maxima of a function that is subject to stress and displacement restrictions, equality constraints, and a separate optimality standard. Optimal starts are sought in feasible direction procedures from a place that meets all restrictions. Using the iterative technique below, the point is then walked to a better point:

$$
X_{i+1}=X_{i}+\varphi S_{i}
$$

where $X_{i}$ and $X_{i+1}$ are starting point and endpoint of $i$ th iteration; $\varphi$ the distance of movement, and $S_{i}$ is movement direction; whose value predefined to make $\mathrm{Xi}+1$ fall within the reasonable area. Si determines the investigation direction and is established on two basic principle: (1) a modest change that does not violate restrictions, and (2) a change that reduces the importance of the goal function. As a result, after several cycles, the best result can be achieved. To reduce computing expense, scientists may occasionally include approximated techniques into these gradient-based optimization procedures. These approaches begin by establishing an approximation of the structural design issue established on structural analysis, so we use optimization techniques to solve the estimated problem.

The best solution to the estimated difficulty is utilized as a starting point for more investigation and improvement of design [73].

These gradient-based optimization approaches were widely used in early structural optimization studies in bridge engineering, and they are also known as conventional procedures. For instance, Chan [72] a linear programming method was used to optimize structures that are vulnerable to more than one loading. These two researcher Dobbs and Felton employed a steepest downfall nonlinear programming approach for truss form optimum design for reducing the structure's volume. Lin et al. [13] For minimal weight design of buildings under static and dynamic constraints, a bi-factor a-b approach, which is a beneficial iteration algorithm and relates to the feasible direction techniques, was developed. According to previous research, these gradient-based methods have a number of drawbacks, despite their wide range of applications. In general, these restrictions are further disperse into three categories:

- Convergence to the global optimized structure is challenging to obtain using these gradient-based techniques in several bridge engineering structural optimization experiments [72]. If the starting design and search directions are not sufficiently separated, these gradientbased approaches possibly converge close to any local optimums among all, in a structural optimization problem. To put it another way, mentioned algorithms are mostly trapped in a local optimum rather than attaining the global optimum.

- Computing gradient regulation is inefficient and difficult to implement [74]. Gradient-based techniques, as a result, are unable to solve the optimization issue of large members with nonlinear, discontinuous and implicit constraints;

- A number of gradient-based techniques include explicit optimization constraints that limit their applicability.

Heuristic methods are a new type of mathematical programming methodology that was developed to meet the needs of structural optimization while avoiding the limitations of gradient-based algorithms.

Heuristic approaches to problem solving are problemsolving techniques that rely on trial and error to arrive at a solution. This type of optimization technique employs a variety of machine learning approaches, i.e. artificial neural networks [75] and support vector network machine [76], increase precision of outcomes via iterations. Heuristic techniques are simple to build and have a lot of computing power, but they are problem-specific and can become stuck in a local optimum. As a result, academics have developed remotely evolved heuristic methods, often known as metaheuristic techniques, to improve optimization outcomes. Metaheuristic techniques are not dependent on 
Table 2. Algorithm and their references.

\begin{tabular}{lll}
\hline Year & Algorithm & References \\
\hline 1998 & Genetic Algorithms & {$[135]$} \\
2006 & An ant colony optimization & {$[136]$} \\
2007 & Modified shuffled frog-leaping optimization algorithm & {$[137]$} \\
2010 & An improved particle swarm optimization algorithm & {$[71]$} \\
2011 & Effective global harmony search algorithm & {$[138]$} \\
2011 & Global Optimization Algorithm & {$[139]$} \\
2013 & Generalized Pattern Search Algorithm & {$[140]$} \\
2014 & Hybrid glowworm swarm algorithm & {$[20,141]$} \\
2015 & Anti-sway algorithm & {$[142]$} \\
2017 & Enhanced discrete particle swarm optimization & {$[143]$} \\
2017 & Hybrid evolutionary algorithm & {$[141]$} \\
2018 & Artificial fish swarm algorithm & {$[144]$} \\
2019 & Simulated annealing & {$[145]$} \\
2020 & ANFIS and LAPO Algorithm & {$[21]$} \\
2021 & Hybrid chaotic whale optimization algorithm & {$[146]$} \\
\hline
\end{tabular}

problem and use different trade-off randomization to go from local to global search. That sort of optimization technique has been more prominent in the study of optimization of structure during the last several years [22].

Realistic or man-made events are frequently used to drive metaheuristic methods i.e. ant colony [77], water flow, and an ensemble of musicians [78]. Some illustrations of the metaheuristic techniques in addition to genetic algorithm (GA) [79,80], harmony search (HS) [81], firefly algorithm (FA) [82], Tabu search (TS) [83], artificial bee colony (ABC) [84], teaching-learning-based optimization (TLBO) [85], particle swarm optimization (PSO) [86], bat algorithm (BA) [87], cuckoo search (CS) [79], and many others. To characterize metaheuristic algorithms, taxonomies founded on specific features of algorithms are created [88], Nature-inspired vs. non-nature-provoked objective functions, population-based vs. trajectory-based objective functions, and dynamic vs. static objective functions are only a few examples. Regardless of differences, among all these metaheuristic algorithms share two key characteristics: Exploration and extraction are two different things [89]. Exploration seeks to provide a range of outcomes for comparison, whereas exploitation is utilized to find best answer currently available. Finally, the global optimum outcome effectively achieved by fair balance of exploration and exploitation.

As shown by four properties described below, metaheuristic algorithms provide a variety of benefits over standard deterministic and stochastic optimization techniques [84]. Metaheuristic methods may be used for both sequential and discrete design variables in combinatorial optimization problems. Furthermore, metaheuristic algorithms do not consider whether or not gradient data is available. Third, the convexity of an explicit connection between the goal function and constraints is not required for metaheuristic algorithms. Fourth, metaheuristic algo- rithms are more effective in locating the best overall solution. There have been numerous successful metaheuristic applications in structural optimization. For illustration, Kociecki and Adeli [90] a two-phase GA for size and topology optimization was developed to minimize the total weight of frame member with rectangular hollow structural components.

Despite the advantages and widespread uses described above, prior studies have found that metaheuristic algorithms have certain flaws and limitations. As an example, Sörensen [91] Metaheuristic algorithms are challenging to design and evaluate on a limited number of specimens with modest structural changes, according to the research. While metaheuristic algorithms are capable of producing good outcomes, this does not imply that are superior to constructive heuristic algorithms. Saka et al. [15] explained metaheuristic algorithms drawbacks; they are computationally costly, particularly while applying on large and complicated structures that are subjected to a range of stresses. According to Mahdavi et al. [92], the major disadvantage of classical metaheuristic algorithms, it successfully solve high-dimensional difficulties due to high landscape complexity, and vast design space (search space). As a result, a number of new structural optimization studies propose that present optimization methods should be improved. Founded on the properties for every metaheuristic algorithm, these algorithm modification techniques aim to improve optimization efficiency. i.e. Cheng et al. [93] Formulated a hybrid HS algorithm that retained traditional HS algorithm's harmony memory and pitch adjustment features while replacing the randomization function with PSO search and neighborhood search for global optimum. When compared to traditional metaheuristic algorithms, this hybrid method has demonstrated to perform well in terms of solution precision and convergence rate. Further, Cao et al. [28] assumed four techniques to 
enhance the achievement of the traditional PSO algorithm: (1) (2) merging PSO with diverse metaheuristic approaches, (3) integrating traditional gradient-based methods with PSO, and (4) restoring conventional global topology with various local topologies These approaches increase the traditional PSO algorithm's searchability for finding a global optimum, as well as its exploitation ability to improve the convergence rate and precision of results. Table 2 summarizes the findings of a number of additional structure optimization experiments that included improved metaheuristics. Although there are many additional metaheuristic algorithms, each one focuses on enhancing a different aspect (capacity) of the original method. As a result, choosing the right approach for a specific optimization problem is crucial for getting the best design while keeping computational costs down.

In addition to increasing algorithm performance, reducing the time-consuming inspections of optimization objectives or constraint functions in the optimization method is another way to improve optimization efficiency. However, because this technique may result in an optimization outcome that differs from the optimization goal, it is not explored in this article.

Apart this, gradient-based and heuristic optimization approaches, reliability-based design optimization (RBDO) techniques stand out. By examining the structural system's issues, such as dimension, material, model, loads, and so on, RBDO intends to find best balance between the cost of structure and security [94]. As a result, this optimization approach gives a minimal degree of dependability, providing designers a place to start. The two-level method, single loop approach, and decoupled approach are the three basic types of RBDO methods. Despite these benefits, these RBDO approaches have significant limitations, as the high computational cost of the dependability analysis every iteration and difficulty of estimating probabilistic constraint gradients, which limit their application in bridge structural optimization.

\subsection{Computational tools and design platforms}

Following structural analysis and modeling, optimization problem formulation, and methodologies, it's critical to use appropriate computational and design tools programs to run optimization programs and codes, and obtain the optimal structural design. For structural design and analysis, manual computations and trial and error were formerly employed, resulting in a high degree of labor and a substantial risk of inaccuracy. A multitude of computational and design tools platforms have emerged as a result of the advancement of information technology to provide environment for structural modeling, design, and analysis. Few well-known software packages, such as ANSYS [95], BIM [96], ABAQUS [97] Significantly improve computation speed and get acceptable results. However, not all software packages work as well as others. When dealing large-scale structures, several existing software packages have been shown to be somewhat successful. Meanwhile, software based on building information modeling (BIM), which is often used for structural design and visualization, is plagued by data interoperability issues [98].
Because software speed has a direct impact on optimization efficiency, selecting the right software to execute structural optimization is crucial. After establishing the issue formulation and optimization approach, the optimization procedure usually proceeds in the following order: solution encoding, mathematical computing, structural calculation, and design. When employing metaheuristic operators, two encoding techniques are used: natural encoding, which uses significances to present binary encoding, and design variables which uses binary strings to represent the design variables. The encoding strategy selected is dictated on the metaheuristic algorithm employed since each algorithm acts differently [67]. After that, two sorts of software packages are used to optimize the structure: computational software and design software. The former is for running optimization programs, while the latter is for structural analysis and design. The computing program is stuck in the iterative phase of the optimization, and each iteration yields a set of values for the design variables.

MATLAB is a commonly utilized computing software in structure optimization because of its excellent calculation and programming capabilities. For topology optimization, Yang et al. [24] proposed a modified bidirectional evolutionary structural optimization (BESO) approach that they applied using MATLAB software.

BIM software is a popularly borrowed type of structural research, design, and visualization software. However, in the same way to get best design, the structure information from BIM environment should be transferred to finite element analysis programs like ETABS, ABAQUS, ANSYS, and SAP.

Some researchers already agreed a single integrated platform to execute whole optimization of structure method, rather of using two types of software and executing mathematical calculations, structural analysis, and design. In SAP2000, a wrapper was created to call the MATLAB toolbox's fmincon function. This method does not need the use of computational tools in the optimization process, nor does it necessitate data manipulation.

Although the majority of the papers in this collection do not go into great detail on computational tools and design platforms, they are essential since they may have a big influence on optimization efficiency. The current tools are confident in their capacity to convince computational and design rules. Regardless, new tools or platforms to increase optimization capacity, computational efficiency, and data interchange are still needed.

\section{Limitations and future work}

\subsection{Quantification of optimization objectives}

Prior to employing mathematical analysis to find the best answer, researchers must first construct a mathematical quantification of the goal. In structural optimization, there are several common quantification methodologies. For example, cost of structure often expressed as structure's volume. The words total strain energy and compliance are frequently called for characterize structural stiffness. Theoretically, properties of structure, including beauty 
of structure, can be presented as optimization targets if they are well characterized [99]. However, it might be difficult to accurately assess motives in particular situations. Aldwark and Adeli [72] Structural designers have long time concept of the efficacy of utilizing structure volume to predict overall cost of structure. Although aiming for the less volume minimum material costs, which include large portion of the whole structural cost, the entire cost still includes carrier and facility fees. As a result, the weight of the structure has no immediate impact on the total cost.

While optimizing the design of continuous reinforced concrete girder, Sharafi et al. [100] employed an objective to reduce formwork and material costs. Some academics employ the parametric mixed-integer non-linear programming (MINLP) technique for structure optimization to reduce the cost. References [101,102], that a mathematical programming method that uses nonlinear objective functions and constraints to optimize the discrete system structure and subsequent parameters at the same time [103]. Highly combinatorial, Large-scale, and highly nonlinear problems are typically solved using the outer approximation/equality-relaxation $(\mathrm{OA} / \mathrm{ER})$ technique and the extended generalized Bender's decomposition (GBD) algorithm, both part of the MINLP strategy [103]. Material unit price, hourly labor costs, assessed loads, structure lengths, steel and concrete classes, and other structural cost-affecting design characteristics are all designed using the MINLP approach and accompanying algorithms. Reference [101] may be taken into account simultaneously with the creation of the objective function, resulting in a good optimization result. The difficulties in MINLP, on the other hand, are particularly difficult to comprehend because they cover all of the subclasses., i.e. the combinatorial nature of mixed-integer programs (MIP) and the complication in solving nonconvex (and even convex) nonlinear programs (NLP) [103]. As a result, the application of the MINLP approach is limited.

Despite these accomplishments, there is no commonly acknowledged structural cost measurement since researchers would integrate multiple structural cost components in various optimization tasks. As a result, future research is expected to recommend a detailed system for structural cost assessment that includes material costs, transportation costs, and invention and formation costs related to construction technique (e.g., precast or cast in place) and standardization rates for structural elements. In order to construct such a system, structured cost data from existing operations must be gathered, and a cost assessment system based on in-depth analyses of existing project data must be built. Furthermore, more accurate quantifications of structural mechanical and aesthetic qualities appear to be on the horizon, allowing these characteristics to be addressed as structural optimization goals.

\subsection{Weighting standards for multi-objective optimization}

Multi-objective optimization, as previously stated, is appropriate and an important topic in the domain of bridge structure optimization since it equated multiple striving optimization aims and so persuades structure developers' regulations. Despite this, the subject of multiobjective structure optimization still has a lot of unresolved concerns. Optimization that takes into account two goals at the same time does not yield a substantial outcome. Although a set of perfect outcomes (Pareto set) is possible, finding one exceptional choice that meets design standards may be difficult. Furthermore, all multi-objective optimization research papers on this website only consider two objectives at a time. In none of these studies, three or more optimization goals were considered at the same time.

Researchers have experimented with a variety of approaches to address the issues highlighted by multiobjective optimization. The concession solution technique, which gives a single best result, is an alternative to Pareto optimality [104]. The best outcome is produced by gradually shrinking the distance between the possible ideal point and the outstanding point, as recommended by this strategy. It is difficult to quantitatively demonstrate the relationship between the two points unless the objective functions have no direction [104]. When dealing with multi-objective optimization, incorporating decisionmakers' priorities is becoming more common. In these strategies, weights are used as parameters to influence decision-makers' intentions. Prior strategies, interactive strategies, and posterior strategies are the three sorts of procedures based on the time period when the decisionmakers' tendencies are given [105]. Prior approaches evaluated the significance of each optimization target before looking for the optimal result. To complement this technique, many weighted standards, such as the linearly weighted standard, have been produced [106], weighted global standard [104] and evaluated scalar-valued achievement norm [107]. In the field of bridge engineering structural optimization, Sanaei and Babaei [108] to maximize the geometry and topology of continuum structures at the same time, researchers applied the weighted sum approach (WSM), which is the simplest and most generally used weighted standards method. This method uses a set of scalar values to interpret the weight of each optimization objective, resulting in single objective functions. As a result, the optimization crisis can be addressed using the single-objective optimization strategy, and a significant optimal result can be obtained. During the search, the interactive techniques provide the decisionmaker with priorities. Regardless, interactive methods are rarely used in the articles chosen, which could be due to differences in the priority information provided by a decision-maker [105]. After the search, the decisionintentions makers are implicated in post-search approaches. The information gathered can be utilized to calculate weighted norms in posterior approaches [104]. For illustration, Zavala et al. [67] they endorsed posterior techniques in their review study on multi-objective structure optimization, where they gave decision-makers outcomes based on an approximation of the Pareto front and subsequently factored in the decision-makers' References.

Despite these achievements, preference-based approaches continue to face significant challenges. That is, regardless of the criteria used to evaluate the objectives, 
it is subjective in some ways. To put it another way, determining whether or not a weighting system is acceptable for a certain task is difficult. Furthermore, decision-makers may not always be able to communicate their priorities for each objective or choose the most appealing conclusion from optimization impacts data [104]. As a result, more research is needed to construct an extended optimization objective weighting network that provides a variety of weight importance based on the methodology utilized, design specifications, and restrictions, allowing researchers to use suitable weighting norms. Although such a weighting system may not be capable of covering all sorts of structural optimization, this network would suffice as a citation when the decision-makers' objectives are unknown. This weighting strategy can also be used to evaluate three or more goals at the same time by integrating multiple objective functions into a single objective function.

\subsection{Application of optimization methods}

Several structural optimization research have sought to build unique methods with a high convergence ratio and good optimal results. However, there has never been a standardized way for assessing the efficacy of optimization methods [109].

Metaheuristic algorithms are only beneficial in particular contexts, as evidenced by the facts and citations above. Each algorithm may be limited to solving a single optimization problem. Even if novel technique or optimization algorithm is developed to solve single optimization problem, its performance for other optimization problems will not be guaranteed, even if it outperforms earlier algorithms for that problem. Furthermore, all of the recently recommended approaches have been evaluated on a range of architectures, which makes comparing the outcomes of these novel algorithms challenging. As a result, the next step should be the creation of a benchmarking network for comparisons of optimization methods to aid the development of new metaheuristic algorithms with better structural optimization application. Making algorithm comparisons easier, structural optimization problems could be categorized into a variety of classes based on structure variations, hierarchies, and more aspects. For each category of optimization problems, a few systematic structural optimization challenges could be identified as benchmark test model problems. Traditional metaheuristic algorithms with reasonable performance for each classification of optimization problems could be utilized as benchmark algorithms in the meantime. The success of any newly recommended algorithm can then be assessed by comparing it to the benchmark algorithms for the relevant classification of optimization problems, as well as the benchmark test difficulties. Fresh optimization algorithms based on the benchmarking technique are intended to develop and discussed wide range of optimization queries with acceptable working performance instead specific optimization problem.

\section{Conclusion}

The findings of this study were scrutinized thoroughly in order to assess previous structural optimization work in the area of bridge structures. Following selection of data, 156 most suitable and relevant papers were found in Google Scholar, Web of Science, and Scopus. The papers in this collection were published between 1970 and 2021. The publishing year, paper kind, journal, geographical area, and optimization aims were all taken into account while statistically evaluating these submissions. The optimization targets' global and geographical trends were also thoroughly explored. In general, amount of published research in this area has risen over time, particularly in nations where the government can afford to fund them adequately. Although cost reduction is the most common optimization goal, recent years have seen a surge in study into multi-objective optimization and structural performance development.

The present exploration, structural optimization limits were recognized, and more effort to break the rules was proposed. Future study could focus on establishing a precise weighting standard for each goal, effectively turning multi-objective issues of optimization to singleobjective problems. More, mathematical quantifications should be constructed in order, so that effectively portray of optimization objectives to carry out optimization process. Despite this, a fundamental technique for assessing the precision of objective quantifications has yet to be devised, which will be necessary. Third, metaheuristic algorithms have restricted applicability. To put it another way, depending on the optimization problem, the outputs of a metaheuristic algorithm can alter. As a result, future research may focus classifying optimization issues according to their building a benchmarking system to each type of optimization difficulty and characteristics, such as standard test problems and model algorithms. Unique optimization algorithms established on the standard system level could be enhanced to effectively solve optimization problem's subset instead tackling a specific optimization problem.

\section{CRediT authorship contribution statement}

Qasim Zaheer: Literature review, Methodology, Data extraction, Writing - original draft; Tan Yonggang: Supervision, review; Furqan Qamar: Supervision, review \& editing.

\section{Declaration of competing interest}

The authors declare that they have no known competing financial interests or personal relationships that could have appeared to influence the work reported in this paper.

Acknowledgments. The authors would like to thank Dalian University of Technology Dalian, China who provided them an opportunity to carry out this research work. 


\section{References}

1. X. Zhou, X. Zhang, Thoughts on the development of bridge technology in China, Engineering 5, 1120-1130 (2019)

2. C. Albuquerque, A.L.L. Silva, A.M.P.D. Jesus, R. Calçada, An efficient methodology for fatigue damage assessment of bridge details using modal superposition of stress intensity factors, Int. J. Fatigue 81, 61-77 (2015)

3. K.L. Scrivener, V.M. John, E.M. Gartner, Eco-efficient cements: potential economically viable solutions for a low$\mathrm{CO}_{2}$ cement-based materials industry, Cement Concr. Res. 114, 2-26 (2018)

4. D. Sen, K. Erazo, W. Zhang, S. Nagarajaiah, L. Sun, On the effectiveness of principal component analysis for decoupling structural damage and environmental effects in bridge structures, J. Sound Vib. 457, 280-298 (2019)

5. K. Manley, T. Rose, Innovation in the road and bridge industry, in 2013 Proceedings of PICMET 2013: Technology Management in the IT-Driven Services (2013), pp. 24682474

6. G. Xu, W. Wang, China's energy consumption in construction and building sectors: an outlook to 2100, Energy 195 , $117045(2020)$

7. C.C. Fu, S. Wang, Computational Analysis and Design of Bridge Structures. CRC Press (2017)

8. B.G. Sumpter, R.K. Vasudevan, T. Potok, S.V. Kalinin, A bridge for accelerating materials by design, Npj Comput. Mater. 1 (October) (2015)

9. B. Briseghella, L. Fenu, C. Lan, E. Mazzarolo, T. Zordan, Application of topological optimization to bridge design, J. Bridge Eng. 18, 790-800 (2013)

10. A. Elrehim, Z. Mostafa, M.A. Eid, M.G. Sayed, Structural optimization of concrete arch bridges using genetic algorithms, Ain Shams Eng. J. 10, 507-516 (2019)

11. H. Toutanji, Design equations for concrete columns confined with hybrid composite materials, Adv. Compos. Mater. 10, 127-138 (2001)

12. R.J. Vanderbei, Structural optimization, Int. Ser. Oper. Res. Manag. Sci. 285, 275-291 (2020)

13. P. Darvishi, S. Shojaee, Size and geometry optimization of truss structures using the combination of DNA computing algorithm and generalized convex approximation method, Int. J. Optim. Civil Eng. 8, 625-656 (2018)

14. L.M. Gil-Martín, E. Hernández-Montes, A. Palomares, M. Pasadas-Fernández, The optimum shape of an arch under non-symmetric loading conditions, Arch. Appl. Mech. 86, 1509-1520 (2016)

15. M.P. Saka, O. Hasançebi, Z.W. Geem, Metaheuristics in structural optimization and discussions on harmony search algorithm, Swarm Evol. Comput. 28, 88-97 (2016)

16. J.A. Hernández Mejía, O. Schütze, O. Cuate, A. Lara, K. Deb, RDS-NSGA-II: a memetic algorithm for reference point based multi-objective optimization, Eng. Optim. 49, 828845 (2017)

17. N. Arabha, A.F. Daneshjoo, H.R. Ahmadi, Multiple damage detection in complex bridges based on strain energy extracted from single point measurement, Front. Struct. Civil Eng. 14, 722-730 (2020)

18. F. Chen, Z. Du, M. Yang, F. Gao, W. Dong, D. Zhang, Design and analysis of a three-dimensional bridge-type mechanism based on the stiffness distribution, Precis. Eng. 51, 48-58 (2018)
19. A. Kaveh, M. Khayatazad, Ray optimization for size and shape optimization of truss structures, Comput. Struct. 117, 82-94 (2013)

20. V. Yepes, J.V. Martí, T. García-Segura, Cost and $\mathrm{CO}_{2}$ emission optimization of precast-prestressed concrete U-beam road bridges by a hybrid glowworm swarm algorithm, Autom. Constr. 49, 123-134 (2015)

21. N.L. Chau, N.T. Tran, T.P. Dao, A multi-response optimal design of bridge amplification mechanism based on efficient approach of desirability, fuzzy logic, ANFIS and LAPO algorithm, Arab. J. Sci. Eng. 45, 5803-5831 (2020)

22. A. Martins, M.B. Luís, M.C. Simões, J.H.J.O. Negrão, Optimization of cable-stayed bridges: a literature survey, Adv. Eng. Softw. 149, 102829 (2020)

23. M. Esade, B. McKelvey, Integrating modernist and postmodernist perspectives on organizations: a complexity science bridge, Acad. Manag. Rev. 35, 415-433 (2010)

24. Z. Xia, A. Li, J. Li, H. Shi, M. Duan, G. Zhou, Model updating of an existing bridge with high-dimensional variables using modified particle swarm optimization and ambient excitation data, Measurement 159, 107754 (2020)

25. A. Mortazavi, A new fuzzy strategy for size and topology optimization of truss structures, Appl. Soft Comput. J. 93, $106412(2020)$

26. S. Zheng, W. Tang, B. Li, A new topology optimization framework for stiffness design of beam structures based on the transformable triangular mesh algorithm, Thin-Walled Struct. 154, 106831 (2020)

27. M. Afzal, Y. Liu, J.C.P. Cheng, V.J.L. Gan, Reinforced concrete structural design optimization: a critical review, J. Clean. Prod. 260, 120623 (2020)

28. H. Cao, X. Qian, Z. Chen, H. Zhu, Enhanced particle swarm optimization for size and shape optimization of truss structures, Eng. Optim. 49, 1939-1956 (2017)

29. S.F. Rahmatalla, C.C. Swan, A Q4/Q4 continuum structural topology optimization implementation, Struct. Multidiscipl. Optim. 27, 130-135 (2004)

30. K. Deb, L. Zhu, S. Kulkarni, Multi-scenario, multi-objective optimization using evolutionary algorithms: initial results, in 2015 IEEE Congress on Evolutionary Computation, CEC 2015 - Proceedings, 1877-1884 (2015)

31. H. Guan, Y.J. Chen, Y.C. Loo, Y.M. Xie, G.P. Steven, Bridge topology optimisation with stress, displacement and frequency constraints, Comput. Struct. 81, 131-145 (2003)

32. J. Chung, K. Lee, Optimal design of rib structures using the topology optimization technique, Proc. Inst. Mech. Eng. C 211, 425-437 (1997)

33. A.R. Mijar, C.C. Swan, J.S. Arora, I. Kosaka, Continuum topology optimization for concept design of frame bracing systems, J. Struct. Eng. 124, 541-550 (1998)

34. H. Wei, B. Shirinzadeh, W. Li, L. Clark, J. Pinskier, Y. Wang, Development of piezo-driven compliant bridge mechanisms: general analytical equations and optimization of displacement amplification, Micromachines 8 (2017)

35. R.T. Terms, NRC publications archive (NPArC) archives des publications Du CNRC (NPArC) Optimization of bridge maintenance management using Markovian models, Span (2014)

36. R. Bowerman, B. Hall, P. Calamai, A multi-objective optimization approach to urban school bus routing: formulation and solution method, Transp. Res. Part A 29, 107-123 (1995) 
37. G. Washer, R. Connor, M. Nasrollahi, J. Provines, New framework for risk-based inspection of highway bridges, J. Bridge Eng. 21, 04015077 (2016)

38. D. Castro e Silva Neto, C.O. Cruz, F. Rodrigues, P. Silva, Bibliometric analysis of PPP and PFI literature: overview of 25 years of research, J. Constr. Eng. Manag. 142, 06016002 (2016)

39. W.S. Ruy, Y.S. Yang, G.H. Kim, Y.S. Yeun, Topology design of truss structures in a multicriteria environment, Comput. -Aided Civil Infrastruct. Eng. 16, 246-258 (2001)

40. S. Sabatino, D.M. Frangopol, Y. Dong, Sustainabilityinformed maintenance optimization of highway bridges considering multi-attribute utility and risk attitude, Eng. Struct. 102, 310-321 (2015)

41. Q.J. Wen, Z.J. Ren, H. Lu, J.F. Wu, The progress and trend of bim research: a bibliometrics-based visualization analysis, Autom. Constr. 124, 103558 (2021)

42. D.H. Bassir, J.L. Zapico, M.P. González, R. Alonso, Identification of a spatial linear model based on earthquakeinduced data and genetic algorithm with parallel selection, Int. J. Simul. Multidiscipl. Des. Optim. 1, 39-48 (2007)

43. P. Qiao, J.F. Davalos, B. Brown, Systematic analysis and design approach for single-span FRP deck/stringer bridges, Compos. B: Eng. 31, 593-609 (2000)

44. H.A. Salim, J.F. Davalos, P. Qiao, S.A. Kiger, Analysis and design of fiber reinforced plastic composite deck-andstringer bridges, Compos. Struct. 38, 295-307 (1997)

45. J. Du, N. Olhoff, Topological optimization of continuum structures with design-dependent surface loading - Part I: new computational approach for $2 \mathrm{D}$ problems, Struct. Multidiscipl. Optim. 27, 151-165 (2004)

46. R. Mark, A.S. Cakmak, K. Hill, R. Davidson, Transactions on the Built Environment (WIT Press, 1993), Vol 3

47. A. Csébfalvi, Combined shape and size optimization of steel bridges, Des. Fabric. Econ. Welded Struct. 53-60 (2008)

48. S. Zhang, H. Li, Y. Huang, An improved multi-objective topology optimization model based on SIMP method for continuum structures including self-weight, Struct. Multidiscipl. Optim. 63, 211-230 (2021)

49. L.M.C. Simes, H.O, Negrxo, Pergamon OM-7949(94) EOO44-3 sizing and geometry optimization of cable-stayed bridges, Comput. Sfru. 52, 3-32 (1994)

50. L.F.F. Miguel, L. Fleck, F. Miguel, Shape and size optimization of truss structures considering dynamic constraints through modern metaheuristic algorithms, Exp. Syst. Appl. 39, 9458-9467 (2012)

51. W. Lingyun, Z. Mei, W. Guangming, M. Guang, Truss optimization on shape and sizing with frequency constraints based on genetic algorithm, Comput. Mech. 35, 361-368 (2005)

52. P.C. Fourie, A.A. Groenwold, The particle swarm optimization algorithm in size and shape optimization, Struct. Multidiscipl. Optim. 23, 259-267 (2002)

53. O. Skoglund, J. Leander, R. Karoumi, Optimizing the steel girders in a high strength steel composite bridge, Eng. Struct. 221, 110981 (2020)

54. S.O. Degertekin, L. Lamberti, I.B. Ugur, Discrete sizing/ layout/topology optimization of truss structures with an advanced jaya algorithm, Appl. Soft Comput. J. 79, 363-390 (2019)

55. N. Ranaivomiarana, F.X. Irisarri, D. Bettebghor, B. Desmorat, Concurrent optimization of material spatial distribution and material anisotropy repartition for two-dimensional structures, Contin. Mech. Thermodyn. 31, 133-146 (2019)

56. E. Design, R. Prototyping, Design Optimization What Is Design Optimization? (2005)

57. S. Sotiropoulos, G. Kazakis, N.D. Lagaros, High performance topology optimization computing platform, Proc. Manufactur. 44, 441-448 (2020)

58. R. Heywood, W. Roberts, G. Boully, Dynamic loading of bridges, Transp. Res. Record 1770, 58-66 (2001)

59. R. Tokerud, Precast prestressed concrete bridges for lowvolume roads, PCI J. 24, 42-56 (1979)

60. Y.L. Zheng, T.P. Zhang, B. Fang, Y.Y. Tang, Discriminant isomap projection, in 2009 International Conference on Wavelet Analysis and Pattern Recognition, ICWAPR 2009 20, 144-147 (2009)

61. J. Hammervold, M. Reenaas, H. Bratteb $\varnothing$, Environmental life cycle assessment of bridges, J. Bridge Eng. 18, 153-161 (2013)

62. M. Liu, D.M. Frangopol, Multiobjective maintenance planning optimization for deteriorating bridges considering condition, safety, and life-cycle cost, J. Struct. Eng. 131, 833-842 (2005)

63. M.D. Thompson, C.D. Eamon, M. Rais-Rohani, Reliabilitybased optimization of fiber-reinforced polymer composite bridge deck panels, J. Struct. Eng. 132, 1898-1906 (2006)

64. A.O. Thippeswamy, Analysis of load optimization in cable stayed bridge using CSI bridge software, Int. J. Appl. Eng. Res. 13, 78-80 (2018)

65. Z. Wang, N. Zhang, X. Du, S. Wang, Q. Sun, Multiobjective optimization of cable forces and counterweights for universal cable-stayed Bridges, J. Adv. Transp. 2021 (2021)

66. Y. Dong, D.M. Frangopol, D. Saydam, Pre-earthquake multi-objective probabilistic retrofit optimization of bridge networks based on sustainability, J. Bridge Eng. 19, 04014018 (2014)

67. G.R. Zavala, A.J. Nebro, F. Luna, C.A.C. Coello, A survey of multi-objective metaheuristics applied to structural optimization, Struct. Multidiscipl. Optim. 49, 537-558 (2014)

68. K. Suresh, A 199-line matlab code for pareto-optimal tracing in topology optimization, Struct. Multidiscipl. Optim. 42, 665-679 (2010)

69. P. Bocchini, D.M. Frangopol, Optimal resilience- and costbased postdisaster intervention prioritization for bridges along a highway segment, J. Bridge Eng. 17, 117-129 (2012)

70. U.M. Diwekar, Nonlinear programming, Springer Optim. Appl. 22, 55-94 (2020)

71. P. Wu, L. Gao, D. Zou, S. Li, An improved particle swarm optimization algorithm for reliability problems, ISA Trans. 50, 71-81 (2011)

72. M. Aldwaik, H. Adeli, Advances in optimization of highrise building structures, Struct. Multidiscipl. Optim. 50, 899919 (2014)

73. F. Edition, 04 - Rao S S - Engineering Optimization Theory and Practice-Wiley (2009). Pdf (2009)

74. Z.H. Han, S. Görtz, R. Zimmermann, Improving variablefidelity surrogate modeling via gradient-enhanced kriging and a generalized hybrid bridge function, Aerosp. Sci. Technol. 25, 177-189 (2013)

75. Y.-H. Huang, Artificial neural network model of bridge deterioration, J. Perform. Construc. Facil. 24, 597-602 (2010) 
76. S.N. Mahmoudi, L. Chouinard, Seismic fragility assessment of highway bridges using support vector machines, Bull. Earthquake Eng. 14, 1571-1587 (2016)

77. S.H. Huang, Y.H. Huang, C.A. Blazquez, G. ParedesBelmar, Application of the ant colony optimization in the resolution of the bridge inspection routing problem, Appl. Soft Comput. J. 65, 443-461 (2018)

78. A. Fox, E. Chew, M. Campbell, E.M. Atkins, H. Hess, Frontiers of Engineering, Front. Eng. (1999)

79. M.A. Mellal, E. Zio, System reliability-redundancy optimization with cold-standby strategy by an enhanced nest cuckoo optimization algorithm, Reliab. Eng. Syst. Saf. 201, $106973(2020)$

80. J.L. Zapico, D.H Bassir, ESDA2008-59553 (2016) 1-6

81. H. Ghodsi, M.J. Khanjani, A.A. Beheshti, Evaluation of harmony search optimization to predict local scour depth around complex bridge piers, Civil Eng. J. 4, 402 (2018)

82. A. Kohansarbaz, A. Kohansarbaz, B. Yaghoubi, M.A. Izadbakhsh, S. Shabanlou, An integration of adaptive neuro-fuzzy inference system and firefly algorithm for scour estimation near bridge piers, Earth Sci. Inf. 14, 1399-1411 (2021)

83. L.B. Morales, Scheduling a bridge club by tabu search, Math. Mag. 70, 287-290 (1997)

84. M.A. Latif, M.P. Saka, Optimum Design of tied-arch bridges under code requirements using enhanced artificial bee colony algorithm, Adv. Eng. Softw. 135, 102685 (2019)

85. G. Bekdas, S.M. Nigdeli, Optimum design of reinforced concrete columns employing teaching-learning based optimization, Chal. J. Struct. Mech. 2, 216-219 (2016)

86. S. Sudha Letha, T. Thakur, J. Kumar, Harmonic elimination of a photo-voltaic based cascaded H-bridge multilevel inverter using PSO (Particle Swarm Optimization) for induction motor drive, Energy 107, 335-346 (2016)

87. R. Khamooshi, J.S. Moghani, Comprehensive harmonic optimization in cascaded H-bridge multilevel inverters using variable DC sources, in PEDSTC 2014 - 5th Annual International Power Electronics, Drive Systems and Technologies Conference (2014), no. Pedstc: 249-254

88. A. Kaveh, Applications of Metaheuristic Methods in Civil Engineering Problems (2017), Vol. 1

89. S. Gholizadeh, Layout optimization of truss structures by hybridizing cellular automata and particle swarm optimization, Comput. Struct. 125, 86-99 (2013)

90. M. Kociecki, H. Adeli, Two-phase genetic algorithm for topology optimization of free-form steel space-frame roof structures with complex curvatures, Eng. Appl. Artif. Intell. 32, 218-227 (2014)

91. K. Sörensen, Metaheuristics-the metaphor exposed, Int. Trans. Oper. Res. 22, 3-18 (2015)

92. S. Mahdavi, M. Ebrahim Shiri, S. Rahnamayan, Metaheuristics in large-scale global continues optimization: a survey, Inf. Sci. 295, 407-428 (2015)

93. M.Y. Cheng, D. Prayogo, Y.W. Wu, M.M. Lukito, A hybrid harmony search algorithm for discrete sizing optimization of truss structure, Autom. Constr. 69, 21-33 (2016)

94. A. Younes, A. Chateauneuf, Benchmark study of numerical methods for reliability-based design optimization, Struct. Multidiscipl. Optim. 41, 277-294 (2010)

95. Z.Y. Ning, Structural optimization research on girder of $200 \mathrm{t}$ bridge crane based on ANSYS, Adv. Mater. Res. 430-432, 1708-1711 (2012)
96. L. Zhao, W. Zhang, W. Wang, Construction cost prediction based on genetic algorithm and BIM, Int. J. Pattern Recogn. Artif. Intell. 34 (2020)

97. K. Deng, P. Pan, Y. Su, Y. Xue, Shape optimization of U-shaped damper for improving its bi-directional performance under cyclic loading, Eng. Struct. 93, 27-35 (2015)

98. Y. Arayici, T. Fernando, V. Munoz, M. Bassanino, Interoperability specification development for integrated BIM use in performance based design, Autom. Constr. 85, 167-181 (2018)

99. D. Chamoret, K. Qiu, M. Domaszewski, Optimization of truss structures by a stochastic method, Int. J. Simul. Multidiscipl. Des. Optim. 3, 321-325 (2009)

100. P. Sharafi, M.N.S. Hadi, Lip H. Teh, Geometric design optimization for dynamic response problems of continuous reinforced concrete beams, J. Comput. Civil Eng. 28, 202209 (2014)

101. S. Kravanja, T. Zula, U. Klanšek, Multi-parametric MINLP optimization study of a composite I beam floor system, Eng. Struct. 130, 316-335 (2017)

102. S. Kravanja, G. Turkalj, S. Silih, T. Zula, Optimal design of single-story steel building structures based on parametric MINLP optimization, J. Constr. Steel Res. 81, 86-103 (2013)

103. M.R. Bussieck, A. Pruessner, Mixed-integer nonlinear programming, Int. Ser. Oper. Res. Manag. Sci. 84, 373-395 (2006)

104. R.T. Marler, J.S. Arora, Survey of multi-objective optimization methods for engineering, Struct. Multidiscipl. Optim. 26, 369-395 (2004)

105. C.A.C. Coello, G.B. Lamont, D.A.V. Veldhuizen, Evolutionary Algorithms for Solving Multi-Objective Problems. Evolutionary Algorithms for Solving Multi-Objective Problems (2007)

106. L.A. Zadeh, Optimality and non-scalar-valued performance criteria, IEEE Trans. Autom. Control 8, 59-60 (1963)

107. T.W. Athan, P.Y. Papalambros, A note on weighted criteria methods for compromise solutions in multi-objective optimization, Eng. Optim. 27, 155-176 (1996)

108. E. Sanaei, M. Babaei, Topology optimization of structures using cellular automata with constant strain triangles, Int. J. Civil Eng. 10, 179-188 (2012)

109. M.P. Saka, Z.W. Geem, Mathematical and metaheuristic applications in design optimization of steel frame structures: an extensive review, Math. Probl. Eng. 2013 (2013)

110. F. Ghodoosi, S. Abu-Samra, M. Zeynalian, T. Zayed, Maintenance cost optimization for bridge structures using system reliability analysis and genetic algorithms, J. Constr. Eng. Manag. 144, 04017116 (2018)

111. A.N. Morab, R.J. Fernandes, Optimization of box girder bridge using genetic algorithm method, IOSR J. Mech. Civil Eng. 15, 24-29 (2018)

112. H.A. Rani, Optimization and effectiveness of bridge construction development based on value engineering, Int. J. Civil Struct. Environ. Infrastruct. Eng. Res. Dev. 7, 15-22 (2017)

113. J.O. Almeida, R.M. Delgado, P.F. Teixeira, A bridge lifecycle cost optimization methodology, in Life-Cycle of Engineering Systems: Emphasis on Sustainable Civil Infrastructure - 5th International Symposium on LifeCycle Engineering, IALCCE 2016 (2017) pp. 1103-1110

114. T.G. Chitari, T.N. Narkhede, Cost optimization of extradosed bridge by varying cable position, Int. Res. J. Eng. Technol. 1462-1474 (2019) 
115. S. Qin, Y.L. Zhou, H. Cao, M.A. Wahab, Model updating in complex bridge structures using kriging model ensemble with genetic algorithm, KSCE J. Civil Eng. 22, 3567-3578 (2018)

116. R.M. Burkart, J.W. Kolar, Comparative $\eta-\rho-\sigma$ pareto optimization of $\mathrm{Si}$ and $\mathrm{SiC}$ multilevel dual-active-bridge topologies with wide input voltage range, IEEE Trans. Power Electr. 32, 5258-5270 (2017)

117. A. Rajguru, Effective techniques in cost optimization of construction project: an review, Int. J. Res. Eng. Technol. 04, 464-469 (2015)

118. W. Zhang, N. Wang, Bridge network maintenance prioritization under budget constraint, Struct. Saf. 67, 96-104 (2017)

119. S. Shuai, Q. Xili, C. Shiyong, X. Yi, O. Huiying, T. Hongbo, H. Xiaoxu, Study on scheme optimization of bridge reinforcement increasing ratio, IOP Conf. Ser. Earth Environ. Sci. 671 (2021)

120. H. Park, Model-based optimization of ultra high performance concrete highway bridge girders 139 (2003)

121. G.H. Eom, S.J. Kim, T.H. Lee, J.H.J. Kim, Design optimization and structural performance evaluation of plate girder bridge constructed using a turn-over process, Materials 10 (2017)

122. D. Bui-Ngoc, T. Bui-Tien, H. Nguyen-Tran, M.A. Wahab, G.D. Roeck, Structural health monitoring using handcrafted features and convolution neural network, Lect. Notes Civil Eng. 110 (2021)

123. V. Penadés-Plà, T. García-Segura, J.V. Martí, V. Yepes, An optimization-LCA of a prestressed concrete precast bridge, Sustainability (Switzerland) 10, 1-17 (2018)

124. T. García-Segura, V. Penadés-Plà, V. Yepes, Sustainable bridge design by metamodel-assisted multi-objective optimization and decision-making under uncertainty, J. Clean. Prod. 202, 904-915 (2018)

125. Z. Yiyun, J. Jiang, Stability behavior of plate girders with laterally unbraced ends, J. Civil Eng. Architect. 10 (2016)

126. E.K. Chalouhi, Optimal Design Solutions of Concrete Bridges Considering Environmental Impact and Investment Cost (2019)

127. M. Ronagh, Plastic hinge length of RC columns subjected to both far-fault and near-fault ground motions having forward directivity, Struct. Des. Tall Special Build. 24, 421-439 (2011)

128. V. Penadés-Plà, T. García-Segura, V. Yepes, Accelerated optimization method for low-embodied energy concrete boxgirder bridge design, Eng. Struct. 179, 556-565 (2019)

129. J. Bennetts, G.T. Webb, P.J. Vardanega, S.R. Denton, N. Loudon, Using data to explore trends in bridge performance, Proc. Inst. Civil Eng. Smart Infrastruct. Construct. 171, 14-28 (2018)

130. Y. Feng, C. Wang, B. Briseghella, L. Fenu, T. Zordan, Structural optimization of a steel arch bridge with genetic algorithm, Struct. Eng. Int. 1-10 (2020)

131. K. Korus, M. Salamak, M. Jasinski, Optimization of geometric parameters of arch bridges using visual programming FEM components and genetic algorithm, Eng. Struct. 241 (2021)

132. C. Liu, A. Hammad, Y. Itoh, Multiobjective optimization of bridge deck rehabilitation using a genetic algorithm, Comput. Aided Civil Infrastructure Eng. 12, 431-443 (1997)

133. S. Tong, Z. Tianqi, S. Li, Z. Hao, Optimal design of negative stiffness devices for highway bridges using performancebased genetic algorithm, Front. Phys. 9, 1-8 (2021)

134. A. Yosri, Y. Elleathy, S. Hassini, W. El-Dakhakhni, Genetic algorithm-Markovian model for predictive bridge asset management, J. Bridge Eng. 26, 04021052 (2021)

135. C.K. Soh, J. Yang, Optimal layout of bridge trusses by genetic algorithms, Comput. Aided Civil Infrastruct. Eng. 13, 247-254 (1998)

136. C. Solnon, D. Bridge, An ant colony optimization metaheuristic for subset selection problems, Syst. Eng. Using Particle Swarm Optim. 3-25 (2007)

137. E. Elbeltagi, T. Hegazy, D. Grierson, A modified shuffled frog-leaping optimization algorithm: applications to project management, Struct. Infrastruct. Eng. 3, 53-60 (2007)

138. D. Zou, L. Gao, S. Li, J. Wu, An effective global harmony search algorithm for reliability problems, Exp. Syst. Appl. 38, 4642-4648 (2011)

139. R. Ahsan, S. Rana, S. Nurul Ghani, Cost optimum design of posttensioned I-girder bridge using global optimization algorithm, J. Struct. Eng. 138, 273-284 (2012)

140. W.M. Li, Z.H. Jiang, T.L. Wang, H.P. Zhu, Optimization method based on generalized pattern search algorithm to identify bridge parameters indirectly by a passing vehicle, J. Sound Vibr. 333, 364-380 (2014)

141. V. Yepes, J.V. Martí, T. García-Segura, Design optimization of precast-prestressed concrete road bridges with steel fiber-reinforcement by a hybrid evolutionary algorithm, Int. J. Comput. Methods Exp. Measur. 5, 179-189 (2017)

142. D. Jolevski, O. Bego, Model predictive control of gantry/ bridge crane with anti-sway algorithm, J. Mech. Sci. Technol. 29, 827-834 (2015)

143. M.D. Phung, C.H. Quach, T.H. Dinh, Q. Ha, Enhanced discrete particle swarm optimization path planning for UAV vision-based surface inspection, Autom. Constr. 81, 25-33 (2017)

144. W. Shi, L. Wang, Z. Lu, Q. Zhang, Application of an artificial fish swarm algorithm in an optimum tuned mass damper design for a pedestrian bridge, Appl. Sci. (Switzerland) 8 (2018)

145. J. Guo, W. Yuan, X. Dang, M.S. Alam, Cable force optimization of a curved cable-stayed bridge with combined simulated annealing method and cubic b-spline interpolation curves, Eng. Struct. 201, 109813 (2019)

146. Z. Xu, M. Huang, Improving bridge expansion and contraction installation replacement decision system using hybrid chaotic whale optimization algorithm, Appl. Sci. (Switzerland) 11 (2021)

Cite this article as: Qasim Zaheer, Tan Yonggang, Furqan Qamar, Literature review of bridge structure's optimization and it's development over time, Int. J. Simul. Multidisci. Des. Optim. 13, 5 (2022) 